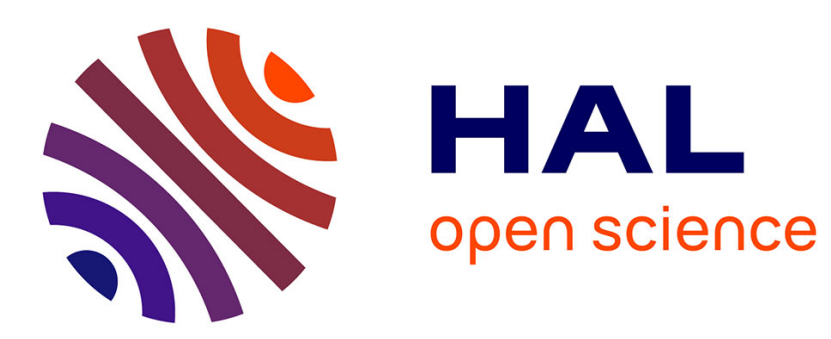

\title{
Evaluation of a new screening assay for HTLV-1 and -2 antibodies for large-scale use.
}

Kerstin Malm, Torbjörn Hans Kjerstadius, Sören Andersson

\section{To cite this version:}

Kerstin Malm, Torbjörn Hans Kjerstadius, Sören Andersson. Evaluation of a new screening assay for HTLV-1 and -2 antibodies for large-scale use.. Journal of Medical Virology, 2010, 82 (9), pp.1606. 10.1002/jmv.21867 . hal-00556039

\section{HAL Id: hal-00556039 \\ https://hal.science/hal-00556039}

Submitted on 15 Jan 2011

HAL is a multi-disciplinary open access archive for the deposit and dissemination of scientific research documents, whether they are published or not. The documents may come from teaching and research institutions in France or abroad, or from public or private research centers.
L'archive ouverte pluridisciplinaire $\mathbf{H A L}$, est destinée au dépôt et à la diffusion de documents scientifiques de niveau recherche, publiés ou non, émanant des établissements d'enseignement et de recherche français ou étrangers, des laboratoires publics ou privés. 


\section{Evaluation of a new screening assay for HTLV-1 and -2 antibodies for large-scale use.}

\begin{tabular}{|r|l|}
\hline Journal: & Journal of Medical Virology \\
\hline Manuscript ID: & JMV-09-1694.R1 \\
\hline Wiley - Manuscript type: & Research Article \\
\hline Date Submitted by the \\
Author: & 06-May-2010 \\
\hline Complete List of Authors: & $\begin{array}{l}\text { Malm, Kerstin; Örebro University Hospital, Dept of Laboratory } \\
\text { Medicine } \\
\text { Kjerstadius, Torbjörn; Karlstad Central Hospital, Dept of Clinical } \\
\text { Microbiology } \\
\text { Andersson, Sören; Swedish Institute for Infectious Disease Control, } \\
\text { Dept of Virology }\end{array}$ \\
\hline Keywords: & \begin{tabular}{l} 
HTLV-1/2, Assay evaluation, Sensitivity, Specificity \\
\hline
\end{tabular} \\
\hline
\end{tabular}

\section{^scholarONE" \\ Manuscript Central}


Table 1. Dilution series of two HTLV-positive specimens

\begin{tabular}{lcc}
\hline Dilution & $\begin{array}{c}\text { RPR207-09 } \\
\text { HTLV-1 } \\
\text { Signal/cut-off } \\
\text { ratio }\end{array}$ & $\begin{array}{c}\text { RPR207-08 } \\
\text { HTLV-2 } \\
\text { Signal/cut-off } \\
\text { ratio }\end{array}$ \\
\hline $1 / 1$ & 149.60 & 113.53 \\
$1 / 10$ & 115.26 & 83.09 \\
$1 / 100$ & 74.82 & 32.47 \\
$1 / 1000$ & 34.06 & 5.88 \\
$1 / 10,000$ & 7.74 & 1.40 \\
$1 / 100,000$ & 2.65 & $0.63^{\mathrm{a}}$ \\
$1 / 1,000,000$ & 1.03 & $0.67^{\mathrm{a}}$ \\
\hline
\end{tabular}

a) Samples with s/co $<1.0$ are rated as non-reactive 
Table 2. Sensitivity and specificity for the Abbott ARCHITECT rHTLV assay

a) Sensitivity

\begin{tabular}{lccc}
\hline \multicolumn{1}{c}{ Sample population } & $\mathbf{n}$ & Number reactive & Sensitivity (95\% CI) \\
\hline HTLV-1 positive & 74 & 74 & $100 \%(94.95-100)$ \\
HTLV-2 positive & 28 & 28 & $100 \%(86.83-100)$ \\
$\begin{array}{l}\text { Quality control samples, } \\
\text { HTLV positive }\end{array}$ & $\begin{array}{c}26 \\
\text { (18 HTLV-1, 7 HTLV-2, } \\
\text { 1 HTLV-1/2) } \\
14\end{array}$ & 26 & $100 \%(85.81-100)$ \\
$\begin{array}{l}\text { Commercial panel } \\
\text { PRP207 }\end{array}$ & $\mathbf{1}$ HTLV-1, 7 HTLV-2) & 14 & $100 \%(73.65-100)$ \\
\hline Overall sensitivity & $\mathbf{1 4 2}$ & $\mathbf{1 4 2}$ & $\mathbf{1 0 0 \%}(\mathbf{9 7 . 3 8 - 1 0 0})$ \\
\hline
\end{tabular}

b) Specificity

Specificity $(95 \% \mathrm{CI})$

Blood donors, HTLVnegative

$100 \%(99.27-100)$

Serum samples with $36-0$

$100 \%(89.75-100)$

rheumatoid factor

Serum samples with 37

(1) autoimmune antibodies

$30 \quad 100 \%(87.70-100)$

Serum samples with antibodies to viral infections $^{\mathrm{a}}$

Previously "falsereactive" samples ${ }^{\mathbf{b}}$

$16 \quad 4 \quad 75 \%(53.80-96.20)$

Overall specificity

$623 \quad 4$

99.36\% (98.35-99.83)

Samples from routine

1412
100\% (99.74-100) diagnostics analysed on ARCHITECT only ${ }^{\mathbf{c}}$ Overall specificity including samples from routine diagnostics

a) $\mathrm{HBV}$ n=10, HCV n=10, CMV n=5, EBV n=5; b) Reactive by the Murex HTLV I/II assay, 12 negative and 4 indeterminate by confirmatory testing; c) Samples analysed between 8 Dec. 2008 and 1 Oct. 2009 at USÖ (analysed fresh). 
Table 3. Previously false-reactive samples, results when tested with the $r$ HTLV I/II assay.

\begin{tabular}{ccccc} 
Nr & Sample origin & $\begin{array}{c}\text { rHTLV s/co } \\
\text { ratio }\end{array}$ & $\begin{array}{c}\text { Murex s/co } \\
\text { ratio }\end{array}$ & Confirmatory result \\
\hline 1 & New blood donor & 0.21 & $\mathbf{2 . 0 8}$ & Negative \\
2 & New blood donor & 0.25 & $\mathbf{1 . 0 3}$ & Negative \\
3 & New blood donor & 0.57 & $\mathbf{1 . 9}$ & Negative \\
4 & Regular blood donor & 0.25 & $\mathbf{1 . 1}$ & Negative \\
5 & New blood donor & 0.19 & $\mathbf{1 . 4 8}$ & Negative \\
6 & New blood donor & $\mathbf{8 . 7 5}$ & $\mathbf{3 . 9 5}$ & Indeterminate \\
7 & New blood donor & $\mathbf{4 4 . 5 1}$ & $\mathbf{1 1 . 4 7}$ & Indeterminate \\
8 & Unknown & 0.82 & $\mathbf{1 . 6 3}$ & Negative \\
9 & New blood donor & $\mathbf{1 . 4 7}$ & $\mathbf{4 . 1 0}$ & Negative \\
10 & New blood donor & 0.26 & $\mathbf{1 . 3 2}$ & Negative \\
11 & Breast milk donor & 0.23 & $\mathbf{2 . 4 8}$ & Negative \\
12 & New blood donor & 0.25 & $\mathbf{1 . 3 9}$ & Indeterminate \\
13 & New blood donor & 0.23 & $\mathbf{1 0 . 4 3}$ & Negative \\
14 & New blood donor & 0.37 & $\mathbf{1 . 0 5}$ & Negative \\
15 & New blood donor & $\mathbf{1 . 1 7}$ & $\mathbf{1 . 2 8}$ & Indeterminate \\
16 & New blood donor & 0.67 & $\mathbf{2 . 4 5}$ & Negative \\
\hline
\end{tabular}

Bold letters indicate reactive result. a) This sample had weak reactivities for $\mathrm{p} 24$ and gp 21 in western blot. A follow up sample one year later had only a weak p24
band. The samples were considered non-infected, but with indeterminate reactivities 
Figure 1. Distribution of signal/cut-off values for 504 negative samples from blood donors

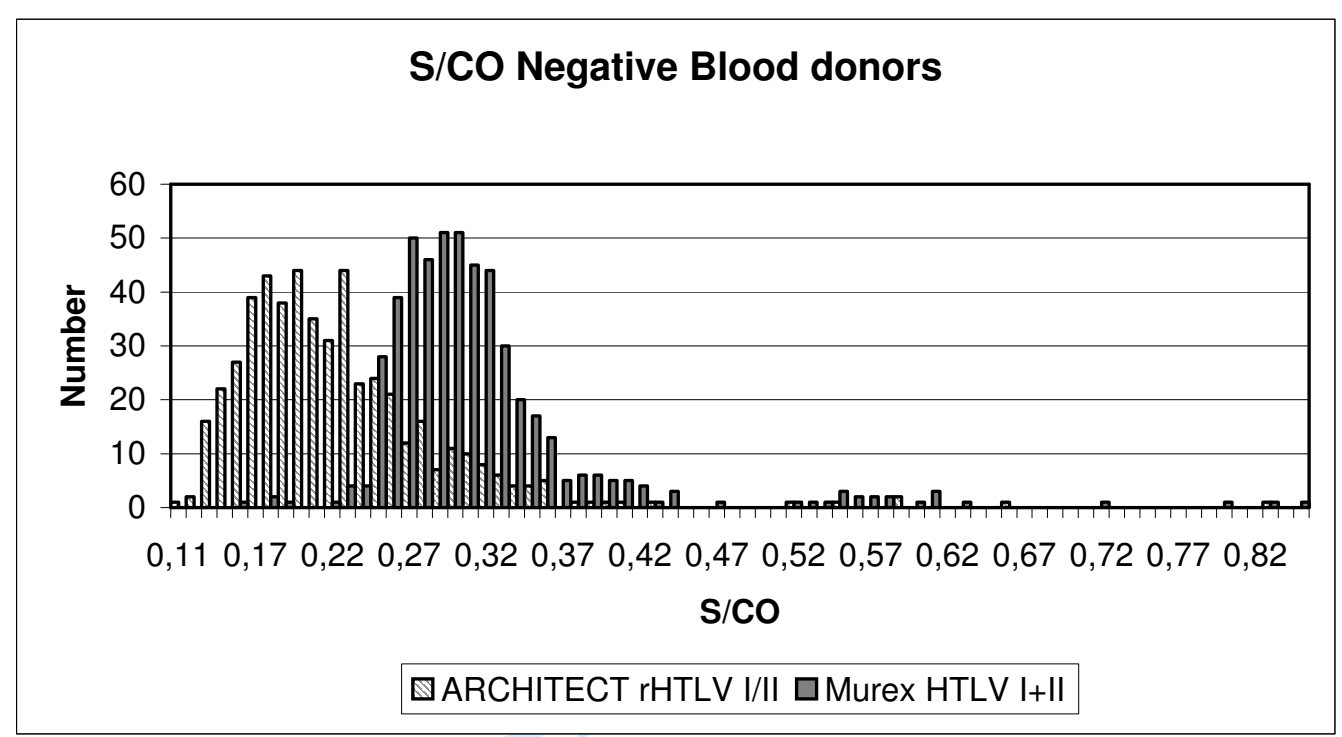

Samples with s/co $<1.0$ are rated as negative. 
1 Evaluation of a new screening assay for HTLV-1 and -2 antibodies for large-scale use

2

3 Kerstin Malm ${ }^{1}$, Torbjörn Kjerstadius ${ }^{2}$, Sören Andersson ${ }^{3}$

4

$5{ }^{1}$ Department of Laboratory Medicine, Microbiology, Örebro University Hospital, Örebro,

$6 \quad$ Sweden;

$7 \quad{ }^{2}$ Department of Clinical Microbiology, Karlstad Central Hospital, Karlstad, Sweden;

$8{ }^{3}$ Departement of Virology, Swedish Institute for Infectious Disease Control, Solna Sweden

9

10 Running title: HTL V-1/2 antibody assay evaluation

14 Key words: HTLV-1/2, assay evaluation, sensitivity, specificity

20 Correspondence to: Kerstin Malm, Department of Laboratory Medicine, Microbiology,

21 Örebro University Hospital, 70185 Örebro, Sweden

22 E-mail: Kerstin.malm@orebroll.se

23 Telephone: +46196021134

24 Fax: +4619127416 


\section{Abstract}

27 Laboratory testing for Human T-lymphotropic Virus type 1 and 2 (HTLV-1 and-2) infections 28 has become routine in blood transfusion, tissue transplantation and clinical diagnoses in many 29 countries worldwide. Screening is usually based on the detection of antibodies to HTLV-1 30 and/or -2. The number of commercially available assays is limited, and among them, ELISA 31 tests based on microtiter format are most commonly used. Recently, the new $r$ HTLV-I/II 32 assay (Abbott Laboratories, Abbott Park, IL, USA) was released; this assay was developed for 33 an automatic large-scale screening platform. This assay was evaluated using pre-characterised 34 serum panels and routine samples from the clinical laboratory. The sensitivity was $100 \%$ for 35 HTLV-1 and -2 (99/99 and 42/42, respectively, including one sample that was dually reactive, 36 HTLV-1+2). To test assay specificity, panels of blood donor sera, specimens from patients 37 with autoimmune diseases and some viral infections were used. False-reactive samples from 38 previous HTLV diagnoses were also included. With these panels, the specificity was $99.4 \%$ $39(619 / 623)$. However, the four false-reactive samples all belonged to the group of samples that 40 were previously considered as false-reactive for HTLV-antibodies. All other samples were 41 negative by the $r$ HTLV-I/II assay, and thus $100 \%$ specificity was obtained. The 1412 42 samples tested in the clinic by this assay in routine use were all negative ( $100 \%$ specificity). 43 Taken together, the overall specificity was $99.8 \%$. The assay was sensitive, specific and 44 appropriate for the large-scale screening of samples for HTLV-1/2 antibodies. 
50

51

52

\section{Introduction}

The human T-lymphotropic viruses type 1 and 2 (HTLV-1 and -2) are effectively transmitted via blood and blood products [Hall et al., 1996, Verdonck et al., 2007]. Therefore, many countries have introduced mandatory screening for HTLV infection of blood and plasma donors. The most cost-efficient mode of screening is by the detection of HTLV-1 or -2 antibodies. Enzyme immuno assays (EIAs) have been used for this screening, and the majority of these EIA screening assays have been based on a microtiter plate format [Andersson et al., 1999; Berini et al., 2008]. Confirmation of screening-reactive specimens has usually been accomplished using immunoblot assays (western blot or line immunoassays) [Thorstensson et al., 2002]. The number of commercially available antibody-screening assays is limited, and the development and release of new assays have been rather few over a period of several years.

Instruments have become increasingly common for use in large-scale screening of blood samples for blood-borne infectious diseases, and assays have been developed for the most prevalent microorganisms and adapted for these instruments [Malm et al., 2009; Kim et al., 2008; Marangoni et al., 2009]. Until recently, no assay for HTLV-1 or -2 has been available on such instruments. With the release of the rHTLV-I/II assay (Abbott Laboratories, Abbott Park, IL, USA) it may be possible to perform a package of screening assays for bloodborne infections that, in many countries, would be specific for microorganisms of regional priority. This will allow an important rationalisation of testing procedures in laboratories that have suitable equipment. It is also the first new commercially available screening assay for HTLV-1 and -2 in many years. This new automated assay for detection of antibodies to HTLV-1 and HTLV-2, $r$ HTLV-I/II, is an immunoassay using a chemiluminescent 
74 The $r$ HTLV-I/II assay has been evaluated using well-characterised panels of sera from

75 HTLV-1 or HTLV-2 infected individuals and various HTLV-negative specimens. The assay

76 showed high sensitivity and specificity, and it is appropriate for use in a large-scale screening 77 package. 
Material and Methods

79

80

\section{Screening immunoassays}

This study evaluated an automated, chemiluminescent immunoassay assay for the detection of antibodies to HTLV-1 and HTLV-2 ( $r$ HTLV-I/II). All assay steps were performed by the automated ARCHITECT $i$ system immunoanalyser (Abbott Laboratories). The solid phase of the assay consisted of paramagnetic microparticles coated with three different antigens; HTLV-1 gp 46 syntetic peptide, HTLV-2 gp 46 syntetic peptide and HTLV-2 gp 21 recombinant antigen. The samples were each mixed with assay diluent, and an aliquot of the mix was combined with the microparticles. After incubation and washing, an acridinium-labelled conjugate with HTLV-1 gp 21 recombinant antigen, HTLV-1 gp 46 and HTLV-2 gp 46 synthetic peptides were added. After another incubation and wash cycle, pretrigger $\left(\mathrm{H}_{2} \mathrm{O}_{2}\right)$ and trigger $(\mathrm{NaOH})$ were added. This resulted in a chemiluminescent reaction, which was measured by the instrument's optical system as relative light units (RLU). The presence or absence of anti-HTLV antibodies was analysed by comparing the chemiluminescent signal to the cut-off signal determined by a calibration step. The ARCHITECT $i$ System calculates the cutoff $(\mathrm{CO})$ by using the mean chemiluminescent signal (RLU) from three replicates of the Calibrator 1 multiplied by 0.25 . The result is shown as a signal-to-cut-off ratio (s/co). Samples with $\mathrm{s} / \mathrm{co}$ ratios $\geq 1.0$ are considered reactive.

The immunoanalyser used, ARCHITECT i2000 (Abbott Laboratories), is a fully automated instrument that performs all the assay steps, from sample collecting to reporting of the result [Hendriks et al., 2000]. The samples that were analysed in this evaluation were also analysed with the Murex HTLV I/II assay (Murex Biotech Ltd, Dartford, United Kingdom), which was the routine assay used by a large proportion of laboratories in Sweden prior to the introduction of the $r \mathrm{HTLV}-\mathrm{I} / \mathrm{II}$ assay. Murex HTLV I/II is a microtiter plate EIA assay . The microtiter-plate wells are coated with HTLV-2 p21 recombinant antigen and HTLV-1 and -2 
103 gp 46 peptides. Sample and reagent addition steps, as well as washing steps, were performed

104 manually with the use of a washing instrument (Anthos Fluido, Anthos Nordstrasse 4,

105 Eugendorf, Austria); samples were read manually using a spectrophotometer (Multiskan

106 Ascent, Thermo Labsystems, P.O. Box 208, Helsinki, Finland). The conjugate in this assay

107 was horseradish peroxidase-labelled HTLV-1 p21 recombinant antigen, HTLV-1 and -2 gp

10846 peptides. The resulting absorbance values were divided by the cut-off value, like the

109 ARCHITECT results, to give an s/co ratio. The cut-off value is determined by adding 0.200 to

110 the mean value of the negative control. All experimental protocols and analyses were

111 performed according to the manufacturers' directions.

112 Serum panels

113 The following samples were used for the evaluation of assay sensitivity:

114 a) Serum panels kept at the Swedish institute for Infectious Disease Control, Stockholm, 115 Sweden (SMI) including HTLV-1 positive samples frpm Guinea-Bissau ( $\mathrm{n}=63$ and

116 Sweden $(n=11)$ and HTLV-2 positive samples from Sweden $(n=28)$. The HTLV-1

117 positive samples from Guinea-Bissau had been collected in previous field studies

118 described elsewhere [Andersson et al 1999, Norrgren et al., 1995, Andersson et al.,

119 1997]. They included samples from occupational cohorts, pregnant women,

120 outpatients clinics and hospitals. The HTLV-2 positive specimens were obtained from

121 intravenous drug users in Stockholm, Sweden, also described previously [Andersson

$122 \quad$ et al., 1995];

123 b) Confirmed positive quality-control samples, (26 total; 18 HTLV-1, 7 HTLV-2, and 1

124 HTLV-1/2). These samples were sent to clinical laboratories for quality evaluation of

125 the laboratory methods during the years 2001-2008. The samples were prepared by

126 the External Quality Assurance in Laboratory Medicine in Sweden (Equalis AB, Box 
127 977, Uppsala, Sweden). Twenty-three of these samples were undiluted, while one 128 sample was diluted $1 / 50$, one $1 / 100$ and one $1 / 1000$;

129 c) A commercial panel consisting of 14 reactive (7 HTLV-1, 7 HTLV-2) and one non130 reactive sample (PRP207, BBI diagnostics, West Bridgewater, Ma, USA). Two of 131 these panel members (one HTLV-1, PRP207-09 and one HTLV-2, PRP207-08) were 132 also serially diluted 10 -fold into six dilutions $\left(1 / 10\right.$ to $\left.1 / 10^{6}\right)$.

133 The following samples were tested to evaluate the specificity of the assay:

134 d) 504 samples from non-reactive blood donors that had tested HTLV-negative using the 135 Murex assay in the past;

136 e) 36 samples from patients with positive rheumatoid factor;

137 f) 37 samples from patients with antibodies associated with autoimmune disease (anti138 nuclear antibodies, SS-A antibodies and/or native DNA-antibodies);

139 g) 30 samples with antibodies/antigens to some viral infections, namely, Hepatitis B 140 (HBV, n=10), Hepatitis C (HCV, n=10), Cytomegalovirus (CMV, n=5) and Epstein$141 \quad$ Barr virus (EBV, $n=5)$;

142 h) 16 samples (14 clinical samples and 2 quality-control samples) that were repeatedly 143 reactive with the Murex assay but regarded as false-reactive, as they could not be 144 confirmed positive with confirmatory assays (12 negative and 4 indeterminate);

145 i) 1412 routine samples that were analysed at the Department of Laboratory Medicine, 146 Microbiology, Örebro University Hospital, Örebro, Sweden (USÖ), from December 2008 to October 2009; these samples were analysed only with the ARCHITECT $148 \quad r H T L V$ I/II assay.

149 The samples in groups c and h were analysed at the Department of Laboratory Medicine, 150 Karlstad Hospital, Karlstad, Sweden (KH), as were 10 samples from group e and 10 samples 151 from group $\mathrm{f}$. The other sample groups were tested at USÖ. Sample groups e and f were 
152 analysed with the Murex assay during this study, while the other samples were tested

153 previously with the Murex assay. All samples were stored at $-20^{\circ} \mathrm{C}$ prior to analysis on the

154 ARCHITECT instrument.

155 The confirmatory assays used in this study were a line immunoblot assay; INNO-LIA

156 HTLV I/II Score (Innogenetics NV, Technologiepark 6, Gent, Belgium) and a western blot

157 assay; HTLV Blot 2.3 (Genelabs Diagnostics, Singapore). The confirmatory assays were

158 performed at SMI, except for the commercial panel, where the assays were performed at BBI

159 Diagnostics.

160 


\section{$161 \quad$ Results}

162 Sensitivity evaluation

163 a) The 102 clinical samples that were confirmed HTLV-positive were all reactive with 164 the ARCHITECT $r$ HTLV assay. The mean s/co ratio for these samples when analysed 165 with the ARCHITECT $r$ HTLV assay was 70.42 (73.96 for HTLV-1, 61.61 for HTLV166 2), with s/co ratios ranging from 1.17 to 149.33 (14.88-149.88 for HTLV-1 and 1.1716787.16 for HTLV-2). Except for one sample ratio (1.17), the s/co ratios for the positive 168 samples were at least five times higher than cut-off. The Murex assay's mean s/co 169 ratio for 93 of these (available) samples was 10.56 (12.10 for HTLV-1, 7.08 for 170 HTLV-2) with s/co ratios ranging from 1.12 to 15.82 (1.40-15.82 for HTLV-1 and 171 1.12-15.00 for HTLV-2).

172 b) All 26 HTLV-positive quality-control samples analysed were reactive with the new 173 ARCHITECT assay. The mean s/co ratio for these samples when analysed with the 174 ARCHITECT $r$ HTLV assay was 97.90 (115.36 for HTLV-1, 51.34 for HTLV-2) with 175 s/co ratios ranging from 35.60 to $151.12(35.60-151.12$ for HTLV-1, $\mathrm{n}=16$ and 48.79 176 to 53.41 for HTLV-2, $n=6$, undiluted samples only). With the Murex assay the mean 177 s/co ratios for the same samples was 14.39 (15.09 for HTLV-1, 12.55 for HTLV-2) 178 179 180 c) All 14 (seven HTLV-1, seven HTLV-2) expected positive members of the commercial 181 182 reactive panel member was non-reactive with the ARCHITECT $r$ HTLV assay. The 183 mean s/co ratio for the panel samples when analysed with ARCHITECT $r$ HTLV assay 184 was 83.19 (89.05 for HTLV-1, 77.32 for HTLV-2) with s/co ratios ranging from 47.20 185 to 149.60 (47.20-149.60 for HTLV-1, and 66.26 to 71.36 for HTLV-2, positive 
186

187

188

samples only). With the Murex assay the mean s/co ratios for the same samples was 11.64 (11.68 for HTLV-1, 11.60 for HTLV-2) with s/co ratios ranging from 11.60 to 11.80 .

The two panel members that were serially diluted 10-fold six times showed an endpoint dilution for HTLV-1 of $1 / 10^{6}$ and for HTLV-2 of $1 / 10^{4}$ (final sample still reactive; Table 1). In all, 141 (98 HTLV-1, 42 HTLV-2 and one HTLV-1/2) samples that were confirmed positive for HTLV-1 or/and HTLV-2 were also positive with the new $r$ HTLV assay. Thus, the sensitivity for the rHTLV assay was $100 \%$ in this study (Table 2).

\section{Specificity evaluation}

d) The 504 previously HTLV-negative blood donors were non-reactive when analysed with the ARCHITECT $r$ HTLV-I/II assay. The mean s/co ratio for these samples was 0.22, compared to 0.32 when analysed with the Murex assay. In Figure 1, the distributions of s/co ratios for these samples are shown.

e) The 36 samples from patients with rheumatoid factor antibodies were all non-reactive with the ARCHITECT $r$ HTLV-I/II assay.

f) The 37 samples from patients with anti-nuclear antibodies, SS-A antibodies and/or native DNA-antibodies were all non-reactive with the ARCHITECT $r$ HTLV assay.

g) The 30 samples with antibodies/antigens to viral infections were all non-reactive with the ARCHITECT $r$ HTLV-I/II assay.

h) Of the 16 samples that were previously regarded as false-reactive, 12 were nonreactive when tested with the ARCHITECT $r$ HTLV assay. Among these, 11 were negative with confirmatory assays for HTLV-1/2, while one sample was indeterminate. Four samples were still reactive when tested with the ARCHITECT rHTLV assay. Three of these were indeterminate with confirmatory tests, one was 
211 negative. If these four samples were considered false-reactive, the specificity for the 212 ARCHITECT $r$ HTLV-I/II assay in this evaluation is 99.36\% (Table 2). More detailed 213 data on the 16 previously false-reactive samples (with the Murex assay) are shown in $214 \quad$ Table 3.

215 i) When the samples from the routine screening at USÖ $(n=1412)$ were included, the 216 overall specificity was $99.80 \%$ (100\% if the preselected Murex false-reactive samples 217 were excluded) (Table 2). 


\section{Discussion}

219 The new ARCHITECT $r$ HTLV-I/II fully automated assay for large scale screening of 220 antibodies to HTLV-1 or -2 has been evaluated. The sensitivity of this assay was high for both 221 HTLV-1- and HTLV-2-positive specimens. The specificity of this assay was high for HTLV222 negative blood donor specimens as well as for samples collected from individuals with 223 various autoimmune disorders or infections known to influence the results of other screening 224 assays, such as EBV infections.

226 The number of commercially available assays for HTLV-1 and HTLV-2 antibody screening is 227 limited. This new assay will be a useful alternative to the available assays. It is performed on 228 the ARCHITECT $i$ system immunoanalyser, which is designed for large-scale screening of 229 blood samples. As this instrument also has assays for other markers for blood-borne infectious 230 diseases, this assay will facilitate the screening process of blood donations and clinical 231 samples, especially in laboratories with large volumes of samples. With just one sample tube 232 it is possible to analyse all the markers needed.

234 It has been shown previously that for several ELISAs used to detect HTLV-1 and -2

235 antibodies it is possible to dilute or pool serum samples up to at least 1/10 and maintain a 236 positive signal [Andersson et al., 2001; Chang et al., 2002]. This may be useful, for example, 237 in studies of the seroepidemiology of large number of samples. Some countries are also using 238 pools of samples established for nucleic acid testing (NAT) screening of blood donors (HIV, 239 hepatitis B and C) for serological HTLV screening. The limited dilution experiment in this 240 study indicates that a pooling strategy, combining 5-10 samples, can be used with the rHTLV $241 \mathrm{I} / \mathrm{II}$ assay. However, it is important to realise that this strategy should not be used for clinical 
242 diagnoses. An extended dilution experiment is also needed in order to conclude the utility of 243 the Architect $r$ HTLV-I/II assay for analyses of pooled samples. the sample to cut-off (s/co) ratios for the $r$ HTLV I/II assay are lower than for the Murex assay. Moreover, the mean s/co values for the positive samples are at least 10 times higher

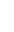
252 ratios between positive and negative samples, which is in accordance with the high specificity 253 observed in this evaluation.

When the screening of large numbers of negative samples is one of the main objectives in the assay, it is important to have a clear separation between the negative values and the cut-off value. This will minimise the risk of scoring samples as reactive when they are not actually positive. As shown in Figure 1, for the negative blood donor samples analysed in this study, than the cut-off level for both HTLV-1 and HTLV-2. Thus, there is a wide separation of s/co bserved in this evaluation.

258 samples were not available for all of them. For instance, it is known that HTLV-2 may be

259 associated with low viral load and low antibody reactivity, which at times may give

260 indeterminate results upon testing [Thorstensson et al., 2002]. Recent reports have also

261 suggested the existence of HTLV-3 and possibly HTLV-4, which may also give indeterminate 262 reactions in common assays for HTLV-1 and -2 [Calattini et al ,2005, Switzer et al, 2006,

263 Wolfe et al 2005]. Of the 16 samples that were previously designated as indeterminate, 12 264 were negative by the $r$ HTLV-I/II assay. Although this may be interpreted as a result of higher 265 specificity for the $r \mathrm{HTLV}-\mathrm{I} / \mathrm{II}$ assay, it is important to remember that other samples with false 266 reactivities may be selected with the $r$ HTLV-I/II assay. 
268 In conclusion, the $r \mathrm{HTLV}-\mathrm{I} / \mathrm{II}$ assay performed well on the serum panels used in this

269 evaluation, and with its design for large-scale screening, it may be a novel tool of high value 270 in the diagnostic arsenal for blood-borne infections. 


\section{$271 \quad$ References}

272 Andersson S, Dias F, Mendez PJ, Rodrigues P, Biberfeld G. 1997. HTLV-I and-II infections

273 in a nationwide survey of pregnant women in Guinea-Bissau, West Africa. J accuir

274 Immune Defic Syndr Hum Retrovirol 15 (4) 320-322

275 Andersson S, Gessain A, Taylor GP. 2001. Pooling of samples for seroepidemiological

276 surveillance of human T-cell lymphotropic virus types I and II. Virus Res 78 (1-2): 101-

$277 \quad 106$

278 Andersson S, Krook A, Käll K, Julander I, Thorstensson R, Biberfeld G. 1995. HTLV

279 infections among Swedish intravenous drug users in 1992. Scand J Infect Dis 27 (6) 547$280 \quad 550$.

281 Andersson S, Thorstensson R, Godoy Ramirez K, Krook A, von Sydow M, Dias F, Biberfeld 282 G. 1999. Comparative evaluation of 14 immunoassays for detection of antibodies to the 283 human T-lymphotropic virus types I and II using panels of sera from Sweden and West 284 Africa. Transfusion 39 (8) :845-51

285 Berini CA, Pascuccio MS, Bautista CT, Gendler SA, Eirin ME, Rodriguez C, Pando MA, 286 Biglione MM. 2008. Comparision of four commercial screening assays for the diagnosis 287 of human T-cell Lymphotropic virus types 1 and 2. J Virol Methods 147: 322-327.

288 Calattini S, Chevalier SA, Duprez R, Bassot S, Froment A, Mahieux R, Gessain A. 2005.

289 Discovery of a new human T-cell lymphotropic viris (HTLV-3) in Central Africa.

$290 \quad$ Retorvirology 2:30.

291 Chang CS, Wu YW, Pan YC, Chen ZY, Wang CS. 2002. Feasibility of human T-

292 lymphotropic virus type I screening using pooled sera. J Formos Med Assoc. 101 (11): $293 \quad 775-778$.

294 Hall WW, Ishak R, Zhu SW, Novoa P, Eiraku N, Takahashi H, da Costa Ferreira M, Azevedo 295 V, Ishak MO, da Costa Ferreira O, Monken C, Kurata T. 1996. Human T Lymphotropic 
296 Virus type II (HTLV-II): Epidemiology, Molecular Properties, and Clinical Features of 297 Infection. J Acquir Immune Defic Syndr Hum Retrovirol. 13 Suppl 1: S204-S214. 298 Hendriks AH, Kortlandt W, Verweij WM. 2000. Standardized Comparision of Processing 299 Capacity and Efficiency of Five New-Generation Immunoassay Analyzers. Clin Chem $300 \quad 46(1): 105-11$

301 Kim S, Kim JH, Yoon S, Park YH, Kim HS. 2008. Clinical performance evaluation of four 302 automated chemiluminescence immunoassays for Hepatitis C virus antibody detection. J 303 Clin Microbiol 46 (12): 3919-23.

304 Malm K, von Sydow M, Andersson S. 2009. Performance of three automated fourth 305 generations combined HIV antigen/antibody assays in large scale screening of blood 306 donors and clinical samples. Transfus Med 19 (2):78-88.

307 Marangoni A, Moroni A, Accardo S, Cevenini R. 2009. Laboratory Diagnosis of Syphilis 308 With Automated Immunoassays. J Clin Lab Anal 23(1):1-6.

309 Norrgren H, Andersson S, Nauclér A, Dias F, Johansson I, Biberfeld G. 1995. HIV-1, HIV-2, 310 HTLV I/II and Treponema pallidum infections: incidence, prevalence, and HIV-2311 associated mortality in an occupational cohort in Guinea-Bissau. J accuir Immune Defic 312 Syndr Hum Retrovirol 9 (4) 422-428.

313 Qui X, Hodges S, Lukaszewska T, Hino S, Arai H, Yamaguchi J, Swanson P, Schochetman 314 G, Devare SG. 2008. Evaluation of a New, Fully Automated Immunoassay for Detection 315 of HTLV-I and HTLV-II Antibodies. J Med Virol 80 (3):484-93.

316 Switzer WM, Qari SH, Wolfe ND, Burke DS, Folks TM, Heneine W. 2006. Ancient origin 317 and molecular features of the novel human T-lymphotropic virus type 3 revealed by 318 complete genome analysis. J Virol 80:7427-7438.

319 Thorstensson R, Albert J, Andersson S. 2002. Strategies for diagnosis of HTLV-I and -II. 320 Transfusion 42 (6):780-91 
321 Verdonck K, González E, Van Dooren S, Vandamme A-M, Vanham G, Gotuzzo E. 2007.

322 Human T-lymphotropic virus 1: Recent knowledge about an ancient infection. Lancet $323 \quad$ Infect Dis 7: 266-281.

324 Wolfe ND, Heneine W, Carr JK, Garcia AD, Shanmugam V, Tamoufe U, Torimiro JN, 325 Prosser AT, Lebreton M, Mpoudi-Ngole E, McCutchan FE, Birx DL, Folks TM, Burke 326 DS, Switzer WM. Emergence of unique primate T-lymphotropic viruses among central 327 African bushmeat hunters. 2005 Proc Natl Acad Sci USA 102:7994-7999. 